This work, result of a research which is still in process and that focuses the aesthetic juvenile production, proposes an escapement far beyond the approved and established scenery of Art. It aims, through a conceptual and empirical investigation, to examine the flows work/quotidian, space/transit and artist/common-person, to create the problem for the territorialization face the overflows and aesthetics reverberations that the practitioners of the quotidian over the walls of the citadel of art produce. We refer to the unauthorized, impure and hybrid productions that, being dispretentious in relation to any approval or legitimization of Art or official sciences, quick cross the screens of the city: mass communication and talks, cultural industry and museums, centralities and social peripherization, schools and street, etc. From the borders to the surplus of the city. Works, spaces and artists get mixed in vagabond and ferocious aesthetics that, despite the circulating theorizations at the metaphorical citadel, constitute a notable aesthetic transit, casually exemplified by the productions of culture of the peripherized youth, as, especially, the funk production. 


\title{
Estéticas nômades: outras histórias, outras estéticas, outros...ou o funk carioca: produção estética, epistemológica e acontecimento
}

\author{
Aldo Victorio \\ FILHO
}

Este trabalho, um dos resultados da pesquisa ainda em processo e voltada para a produção estética juvenil, propõe uma linha de fuga para além do panorama da arte instituída e outorgada. Pretende, via a investigação conceitual e empírica, percorrer os fluxos obra/ cotidianidade, espaço/trânsito e artista/sujeito-comum, para problematizar sua(s) territorializações em face dos transbordamentos e reverberações estéticas que os praticantes dos cotidianos além muros da cidadela da arte produzem. Referimo-nos às produções desautorizadas, impuras e hibridizadas que, despretensiosas com relação a qualquer outorga ou legitimação da arte ou da ciência oficiais, atravessam céleres as telas da cidade: mídias e conversas, indústria cultural e museus, centralidades e periferizações sociais, escolas e rua, etc. Das bordas às sobras da cidade. Obras, espaços e artistas se confundem em estéticas vagabundas e ferozes que, a despeito das teorizações circulantes na cidadela metafórica, constituem um notável trânsito estético, oportunamente exemplificado pelas produções das culturas da juventude periferizada, como é, especialmente, a produção do funk.

Palavras-chave: Estética, arte, juventudes. 
Vários são os aspectos que caracterizam o enorme contingente de jovens marcados pela periferização econômica e social. Tantos outros aspectos também os desenham pela união em torno do fenômeno cultural funk. Muitos gostos, modos de ser e estar no mundo, vocabulário e outras estéticas corporificam o pertencimento funk. Destaca-se, nessa rede, a produção musical e suas notáveis narrativas conhecidas como 'proibidões'. São letras e vozes que nos permitem visualizar o protagonismo juvenil e seus embates meio à teia das relações sociais que fazem de sua cidade, o Rio de Janeiro, Brasil, entre outras características, uma cidade estilhaçada, visto ser um lugar de carências, desencontros, lutas, aspirações, frustrações, interdições e conquistas. Nessas canções os enredos lúdico, estético, coletivo e político propiciam uma admiração privilegiada das emoções e das razões que levam à invenção de novas condições de pertencimento, para as quais concorre a dinamização de redes de práticas e de subjetividades juvenis. É a reinvenção das condições cotidianas diante da inexoralbilidade das estratégias (Certeau). Por meio dos proibides, destacamos a emergência de valores e identidades juvenis da periferia e margens da metrópole que se vinculam à realidade de todo o país, muito por conta dos fluxos dirigidos nas mídias e da significativa presença política, econômica e cultural da cidade no cenário nacional.

Os proibides são canções com poesias peculiares, ritmadas como o funk e o rap, mas caracterizadas, sobretudo, por uma narrativa que inclui o cotidiano militarizado do tráfico de drogas nas favelas e a vida dos seus personagens, além de uma crescente abordagem sexista do gênero. Comercializados clandestinamente, são produzidos nas próprias áreas de controle do tráfico, mas, alcançam um circuito mais amplo; são cds vendidos e adquiridos em toda a cidade e bastantes conhecidos entre os jovens.

Para o estudo de um determinado universo juvenil as definições identitárias são quase inúteis e fatalmente redutórias, na medida em que a clausura dos jovens em um cadastro fixo de grupos ou tribos é um risco permanente. A sociedade brasileira tem como traços historicamente produzidos, o estilhaçamento 
Estéticas nômades: outras histórias, outras estéticas, outros...ou o funk carioca: produção estética, epistemológica e acontecimento

e a assimetria. Condições geradas pela imbatível concentração de renda e insuperável segregação e exploração humana, portanto, para uma eficaz reflexão sobre a educação é urgente a atenção para os mais atingidos no seu mosaico social: os jovens pobres. Certo que a condição econômica não os homogeneíza, na perspectiva deste trabalho, o que unirá os diversos sujeitos componentes da juventude funk, para além da exclusão social, é a estética da produção de suas vidas.

Defendemos, como um oportuno canal de aproximação desses jovens, as produções estéticas que Ihes são caras. Resultados do aproveitamento das sobras da cidade, dos termos às práticas. Surpreendem as suas imagéticas impensáveis e desconsertam as suas poéticas de profana radicalidade. Obragens que mesclam todas as sobras: da indústria cultural às heranças de um passado imemorial no qual a festa e a conjunção coletiva faziam parte da ecologia social, ainda muito distante da radical mercadologização da seminal condição humana, que seria a relação estética com a vida. A compreensão e a valoração dessas realizações juvenis específicas, concebidas a contrapelo das autorizações morais e mercadológica, dependem do reconhecimento do imenso abandono do qual emergem. Abandono flagrante na ausência de efetivos investimentos políticos e na invisibilidade imposta aos meninos e meninas via a rejeição às suas participações na autoria das cidades. Assim a marginalidade do 'outro' é produzida e nesse jogo, o 'outro' tem sua existência e visibilidade reduzidas aos protocolos criados para sua interdição. Sua visibilidade é editada a favor dos atos arbitrários que efetivam sua exclusão e aniquilamento. Assim, a negação da qualidade de suas obras e adesões estéticas é intensificada pela rejeição de qualquer possibilidade poética em suas existências. Tanta negação há de lhes conferir alguma relevância em meio à devastação neoliberal que atinge a maior parte da população do planeta.

Toda obra cultural, aceita como 'arte' ou não, oferece leituras sobre as diversidades e potencialidades dos grupos sociais que as produziram. Temos, então, nas produções 'Funk' um meio útil à elucidação do que faz parte expressiva da juventude ser o que é e enfrentar o que enfrenta. Útil, portanto, ao 
entendimento dos cenários juvenis brasileiros e suas aproximações e afastamentos. Qualquer percepção advinda dessas leituras é um investimento favorável à superação dos desafios da relação com a diversidade e essencial à elaboração e aplicação de ações educacionais cúmplices da autonomia das juventudes.

O esforço da aventura investigativa proposta neste trabaIho reside em três aspectos centrais: o primeiro consiste em destacar o relevo e defender a legitimidade do universo juvenil, historicamente desprezado como produtor de valores culturais e, portanto sociais, desqualificadas, como são, suas criações e práticas cotidianas. O segundo aspecto é a defesa da legitimidade da produção estética do grupo estudado. É, este, um instigante problema, na medida em que, entendida a estética como elemento extremamente importante nos embates pela hegemonia política, todo o universo estético é, portanto, um campo de permanente tensão. O poder é, sempre, legitimado como legitimador das validades artísticas e epistemológicas. Pois, a estética e a arte, assim como a ciência, são meios utilizados na consolidação e manutenção da dominação de alguns, para os quais é imprescindível a fragilização e até a invisibilização de outros. O terceiro aspecto desafiador é o próprio estudo da cotidianidade que, ainda que paulatinamente venha se consolidando como relevante área de saber e importante prática investigativa é ainda encarado com reservas e desconfiança por parte do mundo acadêmico. Os Estudos do Cotidiano representam o encontro de uma perspectiva de abordagem com uma forma muito atual de criar e propor conceituações e aplicar metodologias. A condição de abertura e enredamento conceitual somada à liberdade, que Ihe é característica, é adensada pela capacidade de se reinventar a cada pesquisa, em conformidade com as condições do campo trabalhado. A liberdade de criar ações e de recorrer a teorias diversas confere aos Estudos do Cotidiano a possibilidade de superar qualquer sujeição aos escaninhos da organização científica moderna. Os Estudos do Cotidiano são, por essas razões, os meios mais adequados e menos lesivos de investigar o acontecimento funk em todas as suas linhas de fuga, na medida em que suas práticas investigativas são, por sua contemporaneidade e audácia epis- 
Estéticas nômades: outras histórias, outras estéticas, outros...ou o funk carioca: produção estética, epistemológica e acontecimento

temológica, esteticamente funk!

A abordagem aqui contida, convém sublinhar, é alicerçada pela história de seu autor, ex-professor da educação básica pública, experiência que lhe propiciou forte envolvimento e convívio com as riqueza e dramaticidade das realidades juvenis das quais se ocupa este trabalho. Assim como lhe possibilitou apreender alguns importantes sentidos da potente eloqüência juvenil, via de regra, emudecida pelas pesquisas oficiais, essa atuação docente lhe permitiu, também, dimensionar a fantástica capacidade juvenil de inventar a própria existência meio a tantas dificuldades geradas pelas políticas e práticas dominantes. A relevância da discussão proposta assenta-se, também, na certeza de que a voz e o movimento dos jovens autores e fruidores do FUNK, em sua peculiar territorialidade, são um eloqüente indício da configuração atual da rede social brasileira e de como a temos desenhado para o nosso futuro.

Este trabalho, voltado para a produção estética juvenil, propõe elucidar aspectos relevantes da vida dos jovens 'funkeiros' por meio de uma linha de fuga para além do panorama da arte instituída e outorgada como único território legítimo da produção estética. Assim, via investigação conceitual e empírica, percorreu os fluxos obra/cotidianidade, espaço/trânsito e artista/ sujeito-comum, para problematizar sua(s) territorialização(ões) em face dos transbordamentos e reverberações estéticas que os praticantes dos cotidianos além muros da cidadela da arte produzem. Referimo-nos às produções desautorizadas, impuras e hibridizadas que, despretensiosas com relação à qualquer outorga ou legitimação da arte ou da ciência oficiais, atravessam, céleres, as telas da cidade: mídias e conversas, indústria cultural e museus, centralidades e periferizações, escolas e rua, etc. Das bordas às sobras da cidade. Obras, espaços e artistas se confundem nas estéticas vagabundas e ferozes que, a despeito das teorizações circulantes na cidadela metafórica, constituem um notável trânsito estético, oportunamente exemplificado pelas produções das culturas da juventude periferizada, como é, especialmente, a produção do Funk.

Muitas armadilhas ameaçam essa aventura intelectual, e provavelmente daí se mostre uma das utilidades de seu investi- 
mento e a sua atualidade. Vivemos, na contemporaneidade, o esgarçamento e a tensão do espaço e tempo vividos e em devir. Os regimes de verdade que nos acompanharam e nos garantiram uma convivência amenamente segura com as realidades do mundo, aos poucos foram sofrendo incontornável processo de esfacelamento. A robusta escriturística que os apoiava, por sua vez, foi também atingida por gradual perda de consistência na medida em que os desdobramentos da produção humana avançaram para além da contenção de suas molduras categoriais e de seus cabrestos codificadores.

Se os processos políticos surpreenderam o projeto moderno e frustraram previsões, se a ecologia e a tecnologia, por sua vez, alcançaram deslizamentos inesperados, obviamente seus enredamentos e interferências no universo cultural não se dariam de forma menos dramática ou evitável. Assim, as conceituações sólidas se volatizam, imponderáveis formas de entendimento se vão constituindo líquidas, irrepresáveis e escorregam para além da segurança de qualquer territorialidade fixa. As cercas categoriais/conceituais de um crível universo da arte surpreendem, cada vez mais, a investigação, na medida em que o encaixe de seus blocos-argumentos vai rareando, dando lugar às lacunas quilométricas como nas muralhas metafóricas do império (des) protegido narrado por Kafka e citado por Pelbart (2007).

O nomadismo que invade a cena é muitas vezes, ainda, invisível aos nossos olhos, seja por conta da cegueira provocada pelo desejo de amparo do nosso 'ecoepistêmico sistema', seja por conta da incapacidade da nossa percepção ideologizada de reconhecê-los em sua novidade fenomenológica. Os nômades, os inclassificáveis autores do desconserto estético que atrapaIha a cidade e nesta, a cidadela da arte, interrompem nossos ritos de amor ao que conhecemos e instituímos. Estes 'outros' nos impõem a convivência dolorosa com seus contrastes quase obscenos, suas 'outras' histórias: vida cotidiana comum e produção estética, vidas anônimas como obras de arte. Intimidades escandalosas entre a vida ordinária e a produção estética despossuída de qualquer parâmetro ou norma. Novidades que evidenciam as brechas nas muradas da cidadela, acessos por 
Estéticas nômades: outras histórias, outras estéticas, outros...ou o funk carioca: produção estética, epistemológica e acontecimento

onde os nômades e seus feitos penetram, atravessam e, assim, impõem alguma percepção de suas presenças voláteis, mas concretas, indiferentes, ameaçadoras aos sistemas de verdades da cidadela invadida.

Impõem, os inconvenientes viajantes, por meio dos resíduos e vestígios de suas fixações fugazes, a visão inquietante da inútil realização dos encastelamentos conceituais, dos regimes de certezas partidários que, há tantos séculos, concorrem para a regulação da incontrolável produção estética e corroboram com a canalização das redes estéticas, urdidoras da condição humana, para os balcões do mercado capitalizador das existências. Desses nômades que raramente abandonam a cidade, mas atravessam seus campos estéticos, lançamos mão do funk, para nós um nome que leva a uma complexa rede de vivências, produções e sentidos, sensações e saberes, notavelmente vivida pela juventude carioca, uma juventude funkerizadora da cidade.

\section{Algo sobre o funk}

O funk carioca nasceu de uma miscelânea de ritmos, uma grande quantidade de importações em permanente operação de trocas, incorporações, releituras e assimilações. O Funk, sob muitos aspectos, poderia ser considerado uma reedição da antropofagia de Mário de Andrade. Fenômeno que consumiu e recriou, de forma singular, uma estética própria e original, para além da outorga acadêmica, comercial ou dos mercados culturais. Em primeira e última análise, o Funk é um fenômeno rebelde e desafiador (Essinger, 2005).

Investigar o Funk é um ardiloso desafio que se revela desde os primeiros movimentos de sua abordagem. Pois, quase tudo do que chamaremos de 'rede funk' se espraia além do concreto acontecimento do baile, seu mais importante e concreto evento, o qual, por sua vez, não escapa dos inapreensíveis e inúmeros micro-acontecimentos circulantes em sua grande ação coletiva.

Então, o que dessa grande 'performance' é possível apreender nunca vai além das cinzas do que foi em sua fugaz culmi- 
nância, pois, mesmo que se tente produzir a mais fiel narrativa da experiência vivida, com descrições do instigante espetáculo que é o baile, jamais será possível alcançar a totalidade desse fenômeno.

Nessa perspectiva, é a experiência (estética) empírica da ida ao baile que permite perceber a força dos saberes poderosos que lá circulam e se manifestam. É a estética das performances individuais e coletivas, das danças e modos de estar, de se apresentar e de agir, também individual e coletivamente, o que defendemos como inegável e potente criação e deflagração de saberes. Saberes que, entre outras provocações, desconcertam os regimes de valores-verdades vigentes sobre a arte e a experiência estética.

Regimes, certamente, contaminados pela rede de interesses e crenças burguesas e pela tônica mercadológica que tem prevalecido em quase todas as mediações sociais.

O fenômeno funk ocorre, como qualquer fenômeno cultural espontâneo, livre de demarcações políticas e geográficas, fulgurando tanto nos centros urbanos quanto em regiões mais afastadas. É notável sua fulguração na cidade de São Paulo e em sua periferia, embora com características diferentes do funk carioca. É oportuno registrar que o funk prima pelo deslocamento, é um 'acontecimento' que transita, quando parece repetir-se é quando mais avança e inova. O Funk está diretamente conecto às condições específicas do cotidiano da juventude que o consome e produz, Assim da vida cotidiana cria os elementos poéticos reveladores de sua rede. Regras são reinventadas, normas desconstruídas, muitas condutas descartadas e outras tantas incorporadas.

Como se a ausência de proteção social e a vacuidade de recursos materiais trouxessem a plenitude da liberdade estética, no campo da invenção estética tudo é possível nas zonas de abandono, das quais emerge o acontecimento funkDaí sua formidável força de criação no âmbito das sobras, do relegado, descartado e condenado. Das verdades morais aos valores estéticos. Para compreensão do alcance de nossas afirmações é preciso, junto à leitura dessas reflexões, encarar a decisiva condição dos sujeitos protagonistas da 'rede funk'. Imagens con- 
Estéticas nômades: outras histórias, outras estéticas, outros...ou o funk carioca: produção estética, epistemológica e acontecimento

cretas do abandono político, da desproteção social e tantos outros sofrimentos tornados comuns à população pobre brasileira.

Observamos que nosso estudo é projetado distante de qualquer perspectiva que tome as manifestações populares como eventos hierarquicamente inferiores a qualquer outra produção cultural, portanto, refutamos as perspectivas que tomam o funk como manifestação associável às produções pré-modernas ou que o julguem primitivo, simples ou uma das ações recreativas da 'baixa-cultura'. Refutamos, sobretudo, o entendimento moralista que tem o funk como indício ou resultado de um aventado crescimento da barbárie. Entendemos, em sintonia com a atualidade dos Estudos Culturais, que o Funk enreda forças inaugurais do cimento societal (Maffesoli, 2004), alude à liberação de alguns dos recalques da modernidade e destaca, sobretudo, a dinâmica do contraste entre a simplicidade e a complexidade do 'povo'. Afirmamos, também, que nossa abordagem se projeta do reconhecimento da riqueza cultural do fenômeno funk e de sua importância na compreensão das redes juvenis e de suas potencialidades estéticas e epistemológicas. Dessa maneira, não nos furtamos em assumir o elogio ao Funk.

O funk carioca indicia seu tempo: ocorre em espaços urbanos castigados por grandes problemas ao mesmo tempo em que interage com a mutante paisagem tecno-científico-informacional contemporânea. O cenário funk é configurado por contrastes: contém a precariedade das condições infra-estruturais, a sofisticação tecnológica e a força comunicacional. São estas as condições atuais que emolduram, e dão clima, à geração do funk. Quanto ao seu público e autores, são, predominantemente, constituídos pela juventude atingida pela pobreza e por toda sorte de periferizações decorrentes dão perverso desenho social que diagramou a população brasileira.

Falamos de uma juventude de futuro incerto, na medida em que as políticas públicas não a consideram em suas agendas. A escola e outras emblemáticas instituições que formam a equipagem social e legitimam a participação dos sujeitos na sociedade, Ihes são, também, distanciadas. Esse afastamento é provocado, entre muitas outras colisões, pela rigidez bélica das linguagens e pelo conservadorismo moralista que espreitam as 
práticas curriculares e pedagógicas. Aludimos à resistência da perspectiva cultural burguesa, ainda dominante na educação, às invenções juvenis. A conjunção desta com a emergência do renovado moralismo cristão opera como força de manutenção de um código estético blindado e funciona como filtro das formas e maneiras de viver dos jovens em geral, sobretudo, quando emanam das zonas de abandono da cidade.

O funk não indicia necessariamente a ausência de qualidades culturais e políticas comumente atribuídas a seus autores. Entre as suas significações destaca-se a luta pela autonomia dos jovens que, mesmo não sendo todos autores de canções, são, de uma forma ou de outra, seus criadores. Sobretudo se considerarmos as intensas incorporações e emanações dessa 'estética torta' em seus modos de viver cotidiano e as linguagens adotadas e praticadas. A rede cultural singular dessa juventude se potencializa nas suas práticas cotidianas. Fazeres e saberes, nos quais nunca faltam a música, a exploração estética do corpo, o permanente jogo com a linguagem, a dança, etc. Reiteramos a defesa da rede funk como fonte de conhecimentos estéticos circulantes, uma audaciosa rede que avança indiferente ao sistema de legitimação da arte e aos seus regimes normativos. Em meio à fugacidade de cada uma de suas realizações - dos grandes bailes, muitas vezes reprimido, tantas outras transgressoramente realizados, à circulação desautorizada de suas canções - a rede funk desafia as práticas e moralismos da vigorosa vigilância da parte iluminada da cidade.

A rede funk alerta, em seus espontâneos avanços hibridizantes, que se no âmbito econômico a fragmentação da cidade é de difícil recuperação, no âmbito cultural a organicidade de suas performances desenha uma cidade enredada. Pois, as mediações que viabilizam os encontros entre diferentes 'tribos juvenis', a adesão ao lúdico e à estética funk, reinventam também a reintegração da cidade.

Via o funk é possível entender a juventude periferizada sendo autora da fulguração de sua existencialidade. Pois, cria as condições de sua sobrevivência simbólica, neste caso, inseparável da material. A articidade funk e sua estética infernal existencializa cada um de seus autores e vibra as conexões entre 
Estéticas nômades: outras histórias, outras estéticas, outros...ou o funk carioca: produção estética, epistemológica e acontecimento

suas redes subjetivas, para seus atores, saber e fazer, estética e conhecimento são a mesma obragem.

$\mathrm{Na}$ tessitura do universo Funk não há ações de oposição direta e firmada aos poderes instituídos antagônicos. Contudo, o cotidiano é permeado de desafios e enfrentamentos, como revela a necessidade de reinventar modos de ação e os usos das linguagens em efetiva rebeldia. Embora não possam ser consideradas ações planejadas de oposição sistemática e consciente à regulação e ao controle social, a juventude 'funkeira', com a criação de sua estética, enfrenta tudo que lhe é oposto. Rebelde, age no aproveitamento de chances fugazes e de espaços voláteis. Alimenta-se, e se diverte nas brechas dos espaços e tempos da regulação, talvez pouco, mas sempre o suficiente até a próxima oportunidade. Age na dramática estética das operações de caça (Certeau, 1994) e destes saltos e percalços agencia a vida como obra de arte.

\section{Algumas considerações provisórias}

Evitando as sempre inquietantes maquinações do mercado, cujas operações predadoras inventam estéticas imagéticas de uma juventude eterna e irreal, não podemos desprezar a centralidade da imagem do jovem na produção artística e, sobretudo, musical. Tanto os jovens produzem esteticamente quanto são produzidos pelas redes de interação cultural que dinamizam a contemporaneidade. Assim, as potencialidades e atuações do universo funk demandam ser investigadas como fontes indiciárias da arquitetura social elaborada por seus 'bondes' ou 'galeras', nos quais cada sujeito evidencia sua força como elo social. A marca da insegurança não imobiliza os meninos e meninas em definições estabilizadas, nem tão pouco engendra o seu o devir. Sob a perspectiva do jogo tática versus estratégia (idem, 1994), a estética funk pode significar a ação de uma inusitada ética, enquanto força de criação e manutenção da vida coletiva. Essa rede estetizada tem, entre outras funções, como anunciamos, a de cimento societal e surge como edição atual de antigas práticas de vivificação do coletivo (Maffesoli, 2005). 
Não se pode aceitar que a poemao ou performance discursiva dos personagens presentes nas músicas - sejam os narradores ou os narrados - sejam reduzidas às etiquetações conservadoras de vocabulário euro-referenciado, machista e solidamente moralista. Em sintonia com os modos e maneiras de pesquisar o/com/no/do cotidiano (Alves, 2001), que é nossa escolha metodológica, o que dispomos aqui são notícias sobre um segmento importante da juventude da cidade do Rio de Janeiro. Registrado em um misto de apontamentos e reflexões, que dão forma - pouco ortodoxa - aos resultados de nossa pesquisa. Operação investigativa e dialógica por meio da qual buscamos destacar aspectos fortes, mas invisibilizados, do panorama cultural e social da cidade do Rio de Janeiro. Aspectos que desafiam a educação básica e interrogam o ensino e a institucionalidade da 'arte' na contemporaneidade, além de indiciarem os dramas da cidade.

Assim como qualquer 'estética', a estética funk é política. Nada mais político que a luta cotidiana pela recuperação do espaço comum que é violentamente mercadologizado. Em tal enfrentamento, o jogo das belezas vividas no cotidiano tem utilidade tática. A estética funk, ou sua exploração como força e cimento societal, revela formas de fruir e existir com originalidade antropofágica, transformadoras e sempre criativas de lidar com antagonismos e contrastes sociais e culturais. A estética funk é arma, portanto, no enfrentamento às violências simbólicas e adversidades materiais, assim como tem importância estratégica nos encontros que superam e ultrapassam as barreiras geradas pelas diferenças, sejam sociais, culturais ou de outras ordens. A 'civilidade' outorgada sobrevive via a negação da diferença, e daí resultam a grave desqualificação da estética funk atrelada à acusação a seus autores de tibieza política. Contudo, como Feldman (1994), não os vemos nem como 'passivos', nem 'alienados' pois, permanentemente, criam valores e articulam práticas éticas e estéticas, ao mesmo tempo, em que usam técnicas e tecnologias nas suas redes cotidianas, dentro de processos múltiplos de mediação e hibridização" (Nilda Alves, 2005). Os jovens dos quais falamos, como qualquer sujeito, são criadores e produzem poéticas e narrativas que ali- 
Estéticas nômades: outras histórias, outras estéticas, outros...ou o funk carioca: produção estética, epistemológica e acontecimento

cerçam e respaldam as suas existências. E, sem dúvida, a força dessas criações - política, estética e cultural - é proporcional aos riscos que seus autores enfrentam.

Tomamos também o funk como uma retomada da esttica da existncia (Miskolci, 2006) na qual o corpo tem papel fundamental. Pensar a vida como obra de arte é aceitá-la como prática existencial de fruição, fricção e leitura do/com o mundo, portanto, permanente aceitação de riscos, como qualquer aventura artística.

O nosso trabalho pretendeu, sobretudo, oferecer uma série de considerações a respeito das potências estéticas juvenis que acontecem fora dos espaços outorgados da arte, da cultura e da educação formais, ou seja, na marginalidade oficial. Por meio dessa argumentação, queremos defender, em última análise, uma sociedade mais justa e mais feliz. Sabemos que a nossa fala terá mais chances de êxito partindo do nosso território de atuação mais constante, a arte e seu ensino. Os difíceis tempos de agora nos impõem ousadias, seja na reflexão sobre o já sabido, seja em inusitadas experiências intelectuais. Como a inevitável desconstrução de muitas 'verdades' escoradoras das instituições que nos governam. Aqui, especificamente, a Educação e a Arte. Acreditamos que o território desprestigiado da juventude funkeira seria um excelente ponto de partida e/ ou campo de luta. E muitos são os motivos da nossa crença: trata-se de um universo fortemente estetizado. Trata-se, também - espaotempo da pobreza e desprovido de apoio ou proteção das instituições públicas - de um campo de auto-criação compulsória. Todo processo de criação estética é também de produção de saberes. Daí a nossa escolha da 'rede funk' como espaço privilegiado no qual se conjugam os fazeres da vida e os fazeres intensos da beleza. Um dos interesses de nosso trabalho é enriquecer o debate sobre a arte e seu ensino, inseparável da discussão das tensões entre as centralizações e as periferizações, seja no que tange propriamente à arte, como no que abarca a cultura e a Educação, seus fluxos e enredamentos.

Defendemos, finalmente, a aguda interrogação dos discursos das instituições que aventam para si a regulação e a outor- 
ga do conhecimento e da Arte. Nosso trabalho não se ocupa objetivamente de colocar em xeque a totalidade da Arte e da Educação, contudo, na defesa de uma Educação eficaz e, para tanto, da democratização da Arte, precisaremos interrogar a arte e a educação, e nesta, aquela. Pretendemos, por meio da defesa da beleza que acontece à margem dessas instituições, apontar suas fragilidades e a sua implicação (e ou cumplicidade) na diagramação das mazelas que atingem o povo brasileiro, a começar pela indiferença às potencialidades de sua juventude. Acreditamos que tanto a Educação quanto a Arte podem e devem aprender e revigorar-se com o que produzem as redes juvenis, como exemplificamos com o funk. Por uma sociedade mais justa e uma vida mais bela.

\section{Referências}

ALVES, Nilda; OLIVEIRA, Inês (org.). Pesquisa no/do cotidiano das escolas: sobre redes de saberes. Rio de Janeiro: DP\&A, 2001.

CERTEAU, Michel de. A invenção do cotidiano 1: artes de fazer. Petrópolis, RJ: Vozes, 1994.

CORAZZA, Sandra Mara. Artistagens: filosofia da diferença e educação. Belo Horizonte: Autêntica, 2006.

DIOGENES, Gloria. Itinerários de corpos juvenis: o tatame o jogo e o baile. São Paulo: Annablume, 2003.

ESSINGER, Silvio. Batidão: uma história do funk. Rio de Janeiro: Editora Record. 2005.

GEBAUER, Günter e WULF, Christoph. Mimese na cultura: agir social, rituais e jogos e produções estéticas. São Paulo: Annablume, 2004.

HERSCHMANN, Micael. O funk e o hip-hop invadem a cena. Rio de Janeiro: Editora UFRJ, 2000.

MACEDO, Suzana. Dj Malboro na terra do funck: bailes, bondes, galeras e Rio de janeiro: Prefeitura do Rio. MC's!. Editora Dantes. Livro revista. Coleção Sabastião - Radiografia Carioca, no 3. 2003.

MAFFESOLI, Michel. A Sombra de Dionísio: contribuição a uma sociologia da orgia. São Paulo: Zouk, 2005.

A parte do diabo: resumo da subversão pós-moderna. Rio de janeiro: Record, 2004.

O Tempo das Tribos: o declínio do individualismo nas sociedades de massa. Rio de Janeiro, RJ: Forense Universitária, 2000. 
Estéticas nômades: outras histórias, outras estéticas, outros...ou o funk carioca: produção estética, epistemológica e acontecimento

MISKOLCl, Richard. A vida como obra de arte - Foucalt, Wild e a Estética da Existência. Disponível em: <www.ufscar.br/richardmiskolci/paginas/ academico/cientificos/vidaarte.htm> Acessado em: 20 de out. de 2007. 2006.

.Corpos elétricos: do assujeitamento à estética da existência. Disponível em: <www.scielo.br/scielo.php?script=sci_arttext\&pid=S0104$-026 \times 2006000300006 \&$ Ing $=\& n r m=i s o>$. Acesso em: 21 de out. Estudos Feministas, Florianópolis, setembro-dezembro. 2006.

OLIVEIRA. Inês Barbosa de. Estudos do cotidiano, pesquisa em educação e vida cotidiana: o desafio da coerência. 30 Reunião da Anped in http:// www.fe.unicamp.br/gtcurriculoanped/30RA/30RA-programacao.html.

PELBART, Peter Pál. Exclusão e biopotência no coração do Império. Disponível em: <http://www.cedest.info/Peter.pdf>. Acessado em 20 de out. 2007.

SALLES, Ecio P. de. O BOM E O FEIO: Funk proibidão, sociabilidade e a produção do comum. Disponível em: http://www.pacc.ufrj.br/z/ano3/03/ ecio.htm\#_ednecio.

SMIERS, Joost. Arte sob pressão: promovendo a diversidade cultural na era da globalização. São Paulo, SP: Iluminuras, 2007.

TAYLOR, Roger L.. Arte inimiga do povo. São Paulo, SP: Conrad, 2006.

VIANNA, Hermano (org.) Galeras cariocas: territórios de conflitos e encontros culturais. Rio de Janeiro: Editora UFRJ, 2003.

\section{ALDO VICTORIO FILHO}

Bacharelado em Gravura e Licenciatura em Educação Artística pela Escola de Belas Artes da UFRJ; Mestrado e Doutorado em Educação pela Universidade do Estado do Rio de Janeiro - UERJ. Professor do Programa de Pós-graduação em Artes do Instituto de Artes da UERJ - Linha de Pesquisa 'Arte, cognição e cultura' e da Pósgraduação da Universidade Veiga de Almeida no curso de Especialização em Ensino da Arte. 